\title{
CURSOS SUPERIORES DE TECNOLOGIA NO BRASIL: PESQUISA E INOVAÇÃO ${ }^{1}$ \\ TECHNOLOGY DEGREE COURSES IN BRAZIL: RESEARCH AND INNOVATION EDUCACIÓN SUPERIOR DE TECNOLOGÍA EN BRASIL: INVESTIGACIÓN E INNOVACIÓN
}

\author{
Patricia Murara Stryhalski* \\ *Doutora em Educação pela \\ Universidade do Minho - Portugal e \\ Universidade do Vale do Itajaí (Univali). \\ Mestra em Educação pela Univali. \\ Especialista em Educação Especial \\ pela Fundação Regional de Blumenau \\ Possui graduação em Pedagogia \\ pelo Centro Universitário de Jaraguá \\ do Sul e Complementação em \\ Pedagogia pelo Centro Universitário \\ Leonardo Da Vinci. Compõe o banco \\ de avaliadores do Instituto Nacional \\ de Estudos e Pesquisas Educacionais \\ Anísio Teixeira/Ministério da Educação \\ (Inep/MEC). É professora no Centro \\ Universitário Católica de Santa \\ Catarina e no Centro Universitário \\ Leonardo da Vinci. Jaraguá do \\ Sul, Santa Catarina, Brasil. E-mail: \\ murarapatricia@gmail.com
}

Recebido para publicação em: 11.11.2019

Aprovado em 13.3.2020

\section{Resumo}

Tomando como foco a formação e concepção da pesquisa e da inovação, o presente artigo é um recorte da pesquisa Cursos superiores de tecnologia no Brasil: tradução das políticas públicas do ensino superior nos documentos oficiais e perfis profissiográficos. O objetivo é avaliar até que ponto o texto das políticas públicas voltadas ao ensino superior se traduz nas diretrizes curriculares, no Catálogo Nacional dos Cursos Superiores de Tecnologia e nos perfis profissiográficos dessa modalidade de ensino superior no país.

Palavras-chave: Cursos Superiores de Tecnologia. Pesquisa. Inovação.

\begin{abstract}
Focusing on the formation and conception of research and innovation, this article is an excerpt from the study Technology degree courses in Brazil: translation of public higher education policies in official documents and professional profiles. The objective is to assess the extent to which the text of public policies aimed at higher education is reflected in the curricular guidelines, in the National Catalog of Technology Degree Courses and in the professional profiles of this type of higher education in the country.
\end{abstract}

Keywords:Technology Degree Courses. Research. Innovation.

\section{Resumen}

Centrándose en la formación y concepción de la investigación y la innovación, este artículo es un extracto de la pesquisa Educación superior de tecnología en Brasil: traducción 
de políticas públicas de educación superior en documentos oficiales y perfiles profesionales. El objetivo es evaluar en qué medida el texto de las políticas públicas dirigidas a la educación superior se refleja en las pautas curriculares, en el Catálogo Nacional de Cursos Superiores en Tecnología y en los perfiles profesionales de este tipo de educación superior en el país.

Palabras clave: Educación Superior de Tecnología. Investigación. Innovación.

\section{Introdução}

Os Cursos Superiores de Tecnologia (CSTs) surgem na história do processo de industrialização do Brasil com a nomenclatura de cursos superiores de curta duração, em meados de 1960, com a Lei Federal n. 5.540/68 - também conhecida como Reforma Universitária de 1968 (JUCÁ; OLIVEIRA; SOUZA, 2010). Concomitantemente, uma série de decisões políticas advindas da modernização exigida por esse contexto econômico e político passa a ser implementada por meio de leis, decretos e portarias.

Na Lei de Diretrizes e Bases da Educação Nacional de 1961 (BRASIL, 1961) já havia indícios de cursos diferenciados dos tradicionais, com currículos próprios, chamados de cursos de curta duração. Mas foi somente em 1968 que, de acordo com Brandão (2006), juntamente com a Reforma Universitária, esses cursos diferenciados dos tradicionais começaram a ganhar espaço.

Apesar da aparente inovação, Jucá, Oliveira e Souza (2010) alertam para o preconceito que se criou em relação aos cursos superiores de curta duração, o que fez que deixassem de ser valorizados, pelo fato de erroneamente não serem considerados como progressão nos estudos. Ainda mais, persiste a falsa concepção de que a formação técnica não tem o objetivo de dar uma boa formação às pessoas, e sim apenas atender às necessidades de mercado em um determinado momento da história.

É difícil desfazer uma preconcepção em torno de alguma ideia, mas o que se percebe nas políticas atuais em relação aos tecnólogos não é questão do preconceito, e sim uma política intencional, ratificada por algumas instituições de ensino, de que sejam ofertados cursos que sirvam ao mercado, sem a preocupação de estimular o pensamento crítico.

Diante desse contexto, a delimitação do tema deste artigo reflete do recorte da pesquisa de Stryhalski (2016) intitulada Cursos superiores de tecnologia no Brasil: tradução das políticas públicas do ensino superior nos documentos oficiais e perfis profissiográficos. O enfoque será a relação entre a oferta dos cursos, as expectativas em relação a um curso superior e a concepção de pesquisa e inovação dentro desses programas de formação.

A pesquisa é documental e de cunho qualitativo. Utilizou-se da análise de conteúdo de Bardin (1977) para tratamento dos dados. Analisaram-se 26 CSTs de todas as 
regiões do país e documentos que norteiam sua oferta. Os dados dialogam com diversos autores, como Demo (2011) e Pacheco (2011), assim como com as Diretrizes Curriculares Nacionais Gerais para a Educação Profissional de Nivel Tecnológico (2002); o Catálogo Nacional dos Cursos Superiores de Tecnologia (CNST); a atual Lei de Diretrizes e Bases da Educação Nacional (LDB) - Lei n. 9.394/96; e outros documentos oficiais.

Sendo assim, o presente artigo tem por objetivo avaliar até que ponto o texto das políticas públicas voltadas ao ensino superior se traduz nas diretrizes curriculares e nos perfis profissiográficos dos cursos superiores de Tecnologia no Brasil.

\section{Conceito de pesquisa e inovação}

Antes de abordar como a pesquisa e a inovação estão presentes no discurso dos documentos e perfis profissiográficos, é importante ter clareza do que se entende por pesquisa e inovação. Muitas vezes esses termos são utilizados de forma superficial, sem ter o cuidado com sua essência.

Há certa falta de entendimento acerca da busca por fontes na biblioteca, 0 levantamento bibliográfico e a pesquisa

\subsection{Conceito de pesquisa}

Severino (1994) explicita que a articulação do tripé ensino, pesquisa e extensão baseia-se nas necessidades dos públicos envolvidos na prática da pesquisa: professores e alunos precisam dela para um ensino eficaz e um aprendizado significativo, respectivamente. Já a comunidade espera usufruir os produtos desse conhecimento, enquanto a universidade precisa da pesquisa para ser mediadora da educação.

O conceito de pesquisa é muito difundido, porém, muitas vezes, de forma equivocada. Lüdke e André (1986) comentam que, quando, nas escolas, os professores solicitam para seus alunos pesquisarem determinado tema, o que eles acabam fazendo é uma consulta, muitas vezes cópia do tema solicitado pelo(a) professor(a), chamando-a de pesquisa. Além disso, essa pesquisa pode resumir-se a recorte de reportagens.

Há certa falta de entendimento acerca da busca por fontes na biblioteca, o levantamento bibliográfico e a pesquisa. Muitas vezes, o que ocorre nos bancos escolares é apenas o levantamento bibliográfico para mapeamento de fontes, mas à prática da pesquisa propriamente só se começa a ter acesso a partir do restrito número de pessoas que chegam a ser contempladas com as bolsas de iniciação científica.

Nesse sentido, o conceito de pesquisa utilizado no presente artigo vai ao encontro do pensamento de Lüdke e André (1986, p. 2):

Para se realizar uma pesquisa é preciso promover o confronto entre os dados, as evidências, as informações coletadas sobre determinado assunto e o conhecimento teórico acumulado a respeito dele. Em geral isso se faz a partir do estudo de um proble- 
ma, que ao mesmo tempo desperta o interesse do pesquisador e limita sua atividade de pesquisa a uma determinada porção de saber, a qual ele se compromete a construir naquele momento.

Richardson (1999) aborda que a pesquisa pode ter os seguintes objetivos: resolver problemas específicos (geralmente, de ordem prática), gerar teorias (em relação a questões que ainda não estão claras ou são difíceis de se encontrar) ou avaliar teorias já conhecidas. Mais do que identificar o tipo de relação existente, a pesquisa visa determinar a existência de uma relação, de modo que o processo de testar e formular teorias muitas vezes se confundem:

Quando as teorias claramente formuladas são testadas e confirmadas repetidas vezes e se dispõe de informação empírica consistente, pode-se iniciar nova etapa na formulação de teorias: a procura de constantes matemáticas nas fórmulas que constituem as teorias (RICHARDSON, 1999, p. 17).

Para Lüdke e André (1986), a popularização da palavra "pesquisa" desde a escolarização até o ensino superior compromete seu verdadeiro sentido e até sua qualidade, a qual notadamente só atinge um nível mais elevado na pós-graduação, especialmente na stricto sensu.

\subsection{Conceito de inovação}

Muitas vezes apresentada como consequência da pesquisa, a inovação tem um conceito muito amplo, que permeia vários setores, principalmente, o empresarial, que aposta na inovação tecnológica para se destacar no mercado. "A inovação tecnológica vem sendo crescentemente invocada como estratégia para redimir empresas, regiões e nações de suas crônicas aflições econômicas e para promover o desenvolvimento" (PLONSKI, 2005, p. 25). Nessa linha de pensamento, a inovação faz com que a empresa se mantenha competitiva.

Segundo Fuck e Vilha (2012), o termo inovação surgiu com o economista Joseph Schumpeter (1883-1950), que o associou à ideia de produzir outros itens ou mesmos conquanto que de maneira diferente, conceito que foi se aprimorando ao longo dos tempos. Também Fuck e Vilha (2012) ressalvam que o cuidado conceitual sobre a inovação muitas vezes ainda se perde em um mundo no qual os processos de mudança estão tão presentes que ela é evocada para o centro da análise nos mais diversos tipos e meios.

Para a presente pesquisa, no entanto, o conceito em voga vai ao encontro da Lei da Inovação Tecnológica (Lei n. 10.973/2004), pela qual inovação é a "introdução de novidade ou aperfeiçoamento no ambiente produtivo ou social que resulte em novos produtos, processos ou serviços" (BRASIL, 2004). Ao que pese também Freeman (1982 apud PLONSKI, 2005), um dos estudiosos mais renomados em inovação: "[...] Inovação é o processo de tornar oportunidades em novas ideias e colocar estas em prática de uso extensivo" (FREEMAN, 1982, apud PLONSKI, 2005, p. 27). 
Mas afinal, o que é inovar de fato? Não basta criar algo, se não tiver relevância para a sociedade. Veja-se, por exemplo, o desenvolvimento do forno micro-ondas. Em 1939, Albert Wallace Hull desenvolveu o magnetron², que gera micro-ondas para radares. Dez anos depois, Percy Spencer, por acaso, notou que esse magnetron derreteu o chocolate em seu bolso. Percebeu, assim, que podia ser utilizado para aquecimento de alimentos. Em 1960, de acordo com Nunes (2008), inicia-se a fabricação de fornos micro-ondas para uso doméstico e, em 1975, esses fornos superaram as expectativas devido à sua praticidade e baixo custo, sendo vendidos em larga escala. De acordo com a definição da Lei 10.973/2004, pode ser considerada uma inovação porque resultou na introdução de novidade no ambiente social

Mas afinal, 0 que é inovar de fato? por intermédio de um novo produto.

Cabe aqui ressaltar que, pelo viés econômico, existe uma classificação dos tipos de inovação que as empresas podem utilizar. Conforme Fuck e Vilha (2012, p. 7), pode-se elaborar o quadro a seguir:

Quadro 1 - Classificação da inovação

\begin{tabular}{|l|l|}
\hline Mercadológica & $\begin{array}{l}\text { Envolve a implementação de um novo método de } \\
\text { marketing, com mudanças significativas na aparência e no } \\
\text { produto. }\end{array}$ \\
\hline Organizacional & $\begin{array}{l}\text { Ligada a novos métodos de disposição e gestão das } \\
\text { práticas de negócio da empresa, na organização do seu } \\
\text { local de trabalho ou em suas relações com atores externos. }\end{array}$ \\
\hline Tecnológica & $\begin{array}{l}\text { Introdução de produtos, serviços ou processos produtivos } \\
\text { tecnologicamente novos para a melhoria dos já existentes. }\end{array}$ \\
\hline
\end{tabular}

Fonte: Elaboração própria.

Plonski (2005) complementa dizendo que as inovações tecnológicas em produtos e processos não se excluem mutuamente, ao contrário, combinam-se, por exemplo: a comercialização de DVDs (inovação de produto) pela internet (inovação de processo).

No Brasil, a legislação estabelece o incentivo à inovação e à pesquisa científica e tecnológica no ambiente produtivo, visando, também, ao desenvolvimento industrial, definindo que inovação é a "introdução de novidade ou aperfeiçoamento no ambiente produtivo ou social que resulte em novos produtos, processos ou serviços" (BRASIL, 2004). Ressalta-se que a Lei da Inovação Tecnológica menciona como fundamental o apoio a projetos de pesquisa, ensino e extensão de caráter científico e tecnológico, especialmente nas Instituições Científicas, Tecnológicas e de Inovação (ICTS).

Art. $3^{\circ}$ A União, os Estados, o Distrito Federal, os Municípios e as respectivas agências de fomento poderão estimular e apoiar a constituição de alianças estratégicas e o desenvolvimento de 
projetos de cooperação envolvendo empresas nacionais, ICT e organizações de direito privado sem fins lucrativos voltadas para atividades de pesquisa e desenvolvimento, que objetivem a geração de produtos e processos inovadores.

Parágrafo único. 0 apoio previsto neste artigo poderá contemplar as redes e os projetos internacionais de pesquisa tecnológica, bem como ações de empreendedorismo tecnológico e de criação de ambientes de inovação, inclusive incubadoras e parques tecnológicos (BRASIL, 2004).

Mas será que o Brasil está preparado em termos de profissionais aptos a desenvolverem pesquisas que atendam a demanda da inovação? Os egressos saem das universidades preparados para desenvolver pesquisas? Com conhecimentos suficientes para produzir inovação para o país, conforme sugere a Lei no capítulo 1 no Art. $1^{\circ}$ ? "Esta Lei estabelece medidas de incentivo à inovação e à pesquisa científica e tecnológica no ambiente produtivo, com vistas à capacitação e ao alcance da autonomia tecnológica e ao desenvolvimento industrial do País" (BRASIL, 2004). Nesse sentido, Fuck e Vilha (2012, p. 3) complementam:

A Lei da Inovação Tecnológica (n. 10.973/2004), principal referência legal no tema, foi promulgada em 2005, fruto de uma discussão que vinha amadurecendo a partir dos anos noventa do século passado. Um dos objetivos da Lei é favorecer maior articulação entre Universidade, Instituto de Pesquisas e empresas privadas no que tange às pesquisas científicas e tecnológicas. Ou seja, ampliar o diálogo entre o mundo acadêmico e o empresarial, aspecto particularmente importante para empresas que buscam novas oportunidades e novos mercados.

Veja-se que as universidades têm papel crucial para o desenvolvimento tecnológico inovador, o qual se dá por meio de pesquisas, mas, como alerta Fava-De-Moraes (2000, p. 9):

A participação do financiamento empresarial na pesquisa universitária deve, contudo, merecer muita cautela para que não ocorra 'sigilo e privatização (capitalização) do saber', o que seria um desastre total para os valores acadêmicos.

Ao encontro dos pensamentos de Fava-De-Moraes (2000), faz-se necessário que as universidades e pesquisadores não sejam fortemente influenciados pelo setor produtivo, a ponto de não divulgarem pesquisas e inovações por conta de patrocínios. O autor dá o exemplo ocorrido em 1996:

[...] Quando uma empresa farmacêutica proibiu a publicação de pesquisa aceita por revista científica conceituada, ao saber que fármacos muito mais baratos de empresas concorrentes mostraram-se substitutos terapêuticos eficientes, fato que comprometeria o mercado de sua droga em US\$ 600 milhões anuais (FAVADE-MORAES, 2000, p. 9). 
É necessário tomar

cuidado para que

universidades $\mathrm{e}$

pesquisas não estejam

exclusivamente

a serviço de

patrocinadores
Ou seja, é necessário tomar cuidado para que universidades e pesquisas não estejam exclusivamente a serviço de patrocinadores, uma vez que isso retarda e prejudica o desenvolvimento, seja na saúde, seja na própria questão tecnológica. Ainda assim, o autor alerta que: "[...] a pesquisa básica executada 'espontaneamente' pela Universidade ainda é comprovadamente maior fonte de resultados aplicáveis do que a pesquisa dita 'encomendada' pela empresa” (FAVA-DE-MORAES, 2000, p. 9). Certamente, o setor industrial vê na pesquisa tecnológica um futuro muito promissor em relação à inovação.

\section{0 que dizem os documentos e perfis profissiográficos em relação a pesquisa e inovação?}

Embora o parecer do Conselho Nacional de Educação (CNE) 29/2002 aborde que os Cursos Superiores de Tecnologia possuem características diferenciadas de acordo com seu perfil de conclusão, todos são considerados, por lei, graduação de nível superior e devem ser estruturados à luz das Diretrizes Curriculares Nacionais, aprovados pelo CNE e homologados pelo Ministério da Educação (MEC), "[...] não se abrindo qualquer tipo de exceção" (CONSELHO NACIONAL DE EDUCAÇÃO, 2002, p. 5). De acordo com o Parecer, esses cursos formam para determinada área profissional, para resolver situações operacionais dentro da empresa. No entanto, ao analisar o documento, existe certa contradição. Em outro momento, o texto é o seguinte: "A proposta do MEC apresenta os cursos superiores de tecnologias como 'uma das principais respostas do setor educacional às necessidades e demandas da sociedade brasileira" (CONSELHO NACIONAL DE EDUCAÇÃO, 2002, p. 2). E complementa:

a ampliação da participação brasileira no mercado mundial, assim
como o incremento do mercado interno, dependerá fundamental-
mente de nossa capacitação tecnológica, ou seja, de perceber,
compreender, criar, adaptar, organizar e produzir insumos, produ-
tos e serviços (CONSELHO NACIONAL DE EDUCAÇÃO, 2002, p. 2).

Criar, adaptar, organizar; produzir insumos, produtos e serviços; ou inovar, tudo isso requer investimento em pesquisa. Demo (2011, p. 10) contribui ao dizer que "[...] a pesquisa busca o conhecimento para poder agir na base do saber pensar, a educação busca consciência crítica [...], a pesquisa se torna importante em qualquer curso de graduação por ser essa base do pensar".

Porém, além de investimento em pesquisa, busca-se, de acordo com a LDB (BRASIL, 1996), "estimular a criação cultural e o desenvolvimento do espírito científico e do pensamento reflexivo". A forma como o currículo do curso está organizada contribui para se ter um profissional que, além de atender as necessidades específicas do mercado, também tenha um conhecimento mais aprofundado sobre a ementa do curso. 
Os objetivos dos 26 cursos selecionados para esta pesquisa apresentam o conceito de pesquisa e inovação de forma superficial e muitos nem a mencionam. A organização curricular dos CSTs é em módulos, o que dificulta a sequência para se ter um bom projeto de pesquisa que seja, de fato, o estudo de um problema. Parece haver uma certa falta de identidade nos cursos superiores de Tecnologia. As Diretrizes Curriculares, em determinados momentos, defendem a formação mais voltada para o mercado, de trabalho, como:

A formação do tecnólogo é, obviamente, mais densa em tecnologia. Não significa que não deva ter conhecimento científico. 0 seu foco deve ser o da tecnologia, diretamente ligada à produção e gestão de bens e serviços. A formação do Bacharel, por seu turno, é mais centrada na ciência, embora sem exclusão da tecnologia. Trata-se, de fato, de uma questão de densidade e foco na organização do currículo (CONSELHO NACIONAL DE EDUCAÇÃO, 2002, p. 29).

Em outros momentos, a ênfase a uma formação científica que atenda a pesquisa e a inovação, como na passagem a seguir:

As tecnologias industriais, embora bem-sucedidas, são em sua maioria importadas. Esta talvez seja a razão da atual crise em nossa indústria e da necessidade que ela sente em adquirir competitividade internacional. Para isso é possível que não nos faltem nem engenheiros, nem cientistas competentes e nem um operário habilidoso. O que evidentemente está faltando em nossa indústria e em nossos laboratórios de pesquisa são os tecnólogos (CONSELHO NACIONAL DE EDUCAÇÃO, 2002, p. 30).

Ao admitir que faltam tecnólogos nos laboratórios de pesquisa, o que indica faIha na organização curricular dos cursos e falta de conhecimento do que prevê a legislação para um curso de nível superior, assume-se a falha na elaboração dos cursos e a falta de conexão entre o que dizem os documentos oficiais em relação a pesquisa e inovação e o que evidentemente se está colocando em prática na oferta dos cursos. Os objetivos dos cursos, perfil do egresso e CNST preveem a formação mais densa em tecnologia, contudo imediatista, que dure pouco tempo com vistas a dedicar maior tempo aos processos do mercado de trabalho.

Ao que tudo indica, na elaboração do CNST parece não terem sido levadas em consideração as políticas de educação superior, LDB e diretrizes curriculares. O que se encontra nos catálogos e, consequentemente, nos objetivos dos cursos e perfis profissiográficos são mais voltados aos processos de industrialização.

A LDB prevê para os cursos superiores que a pesquisa se alinha ao princípio científico, que tenha como base a fronteira de conhecimento. Em seu artigo 43:

incentivar o trabalho de pesquisa e investigação científica, visando o desenvolvimento da ciência e da tecnologia e da criação e difusão da cultura, e, desse modo, desenvolver o entendimento do homem e do meio em que vive (BRASIL, 1996). 
Nas palavras de Lüdke e André (1986), o pesquisador é o elo entre o conhecimento acumulado e as evidências extraídas da pesquisa. Desse modo, o que se percebe, a priori, nos perfis profissiográficos e objetivos dos cursos é que o profissional não terá contato com a fronteira do conhecimento, com a pesquisa e, consequentemente com a inovação, mas deverá estar apto a desenvolver determinadas situações e imprevistos que poderão ocorrer no exercício da função.

A impressão que se tem é que a pesquisa está muito distante não só dos cursos tecnológicos como também dos demais cursos superiores. Parece que pesquisar é só dever da pós-graduação stricto sensu, e Demo faz observações muito pontuais a esse respeito: "Pesquisa precisa ser internalizada como atitude cotidiana, não apenas como atividade especial, de gente especial, para momentos e salários especiais" (DEMO, 2011, p. 12). E, ainda: "[...] é mister superar a visão unilateral de considerar como pesquisa apenas seus estágios sofisticados, representados pelos produtos solenes de mestre ou do doutor". (DEMO, 2011, p. 12). A pesquisa está prevista nos documentos oficiais e deveria estar presente em todos os cursos de graduação, não somente nos cursos tecnológicos.

Uma fragilidade que parece haver nos cursos tecnológicos é que houve a oferta em grande número, tanto em instituições públicas como privadas, e só depois definiramse Diretrizes Curriculares Nacionais para uma educação profissional de nível tecnológico. Como as próprias Diretrizes apontam: "É como cumprir a tarefa de "abastecer o avião em pleno vôo" (CONSELHO NACIONAL DE EDUCAÇÃO, 2002, p. 3)". Ou seja, primeiro houve a oferta e depois se pensou na organização e estrutura de fato.

Mesmo com a elaboração das Diretrizes um tanto quanto tardia, o Catálogo Nacional foi elaborado em 2010. Na apresentação, a publicação explicita que foi inspirada nas Diretrizes e em sintonia com a dinâmica do setor produtivo, levando em conta, ainda, "os requerimentos da sociedade atual" (BRASIL, 2010). No entanto nele há indícios mais explícitos em relação ao mercado do que às próprias Diretrizes - as quais previam o papel do tecnólogo na aplicação da tecnologia aplicada em pesquisa (CONSELHO NACIONAL DE EDUCAÇÃO, 2002).

A pesquisa está prevista nos documentos oficiais e deveria estar presente em todos os cursos de graduação
O CNST não traz, aparentemente, a pesquisa e a inovação como algo relevante. Apesar de ser de 2010, a impressão que se tem é de que aquela visão dos anos 1960, quando foram promulgados os primeiros cursos de curta duração, permanece. A preparação científica (pesquisa) ficava a cargo dos engenheiros, e a curta duração, aos tecnólogos que se formariam em três anos e cuidariam apenas dos processos industriais, ou seja, da operacionalização de processos.

Parafraseando Brandão (2006), o tecnólogo tem a capacidade de operar, mas não de produzir novas tecnologias. Esse argumento de Brandão traz a seguinte reflexão: como um profissional saberá operar as tecnologias se não tiver um conhecimento teórico aprofundado? Como inovar? 
O Catálogo, em sua apresentação, propõe que a sua elaboração esteja pautada nas Diretrizes, e tem por finalidade orientar a oferta dos cursos:

O catálogo organiza e orienta a oferta de cursos superiores de tecnologia, inspirado nas Diretrizes Curriculares Nacionais para a Educação Profissional de Nível Tecnológico e em sintonia com a dinâmica do setor produtivo e os requerimentos da sociedade atual. Configurado, deste modo, na perspectiva de formar profissionais aptos a desenvolver, de forma plena e inovadora, as atividades em determinado eixo tecnológico e com capacidade para utilizar, desenvolver ou adaptar tecnologias com a compreensão crítica das implicações daí decorrentes e das suas relações com o processo produtivo, o ser humano, o ambiente e a sociedade (BRASIL, 2010, p. 9).

Na descrição do Catálogo que orienta e organiza cada curso parece haver somente descrição de competências:

A Educação Profissional não é mais concebida como um simples instrumento de política assistencialista ou linear ajustamento às demandas do mercado. Ela é concebida, agora, como importante estratégia para que os cidadãos tenham efetivo acesso às conquistas científicas e tecnológicas da sociedade, que tanto modificam suas vidas e seus ambientes de trabalho (CONSELHO NACIONAL DE EDUCAÇÃO, 2002, p. 352).

A preparação científica dos alunos para futuras intervenções e inovações sociais e amplas dentro de seu próprio campo de atuação carece de mais aprofundamento. Nesse sentido, Pacheco (2011, p. 16) aborda a questão da globalização interferindo nos sistemas educativos:

Ao valorizar a educação e formação como referentes da mudança, a globalização reforça os fundamentos da teoria do capital humano, em que se acentua a visão da educação como processo de formação social, orientada para mercados competitivos, clamando que as organizações educativas devem responder a desafios imediatos.

Nas palavras de Pacheco, tudo indica que a educação está virando um negócio. Por isso, está sendo insuficiente na pesquisa, na inovação e na preparação científica, principalmente nos cursos superiores. No entanto, na presente pesquisa, também verifica-se que, no caso específico dos CSTs, os quais têm carga horária reduzida em relação aos demais cursos superiores, esse aspecto está ainda mais comprometido em relação a pesquisa e a inovação, pressuposto presente na legislação do ensino superior. Diante desse contexto, a Conferência Mundial sobre Ensino Superior de 2009 se pronuncia da seguinte forma:

Instituições de ensino superior, através de suas funções principais (pesquisa, ensino e serviços comunitários) estabelecidas no contexto de autonomia institucional e liberdade acadêmica, de- 
vem aumentar o foco interdisciplinar e promover o pensamento crítico e a cidadania ativa (CONFERÊNCIA MUNDIAL SOBRE ENSINO SUPERIOR 2009, p. 2).

Diante do contexto atual, o pensamento crítico e a cidadania ativa parecem abrir espaço com mais ênfase no processo e na operação de postos específicos na linha de produção. Nesse sentido, quando se pensa em reforma, o que encontra são medidas técnicas "[...] cujas ideias estão centralizadas em pareceres técnicos de grupos de trabalho, politicamente orientados e controlados, sem o sentido real da mudança escolar" (PACHECO, 2011, p. 16). É o que vem sido chamado de "mercadorização do conhecimento".

Nessa linha, pode-se dizer que o CNST traz indícios fortes de "mercadorização", inclusive, do perfil dos egressos e objetivos do curso. Os verbos utilizados para descrever seus objetivos, como implantar, executar, controlar, trazem a sensação de adequação exclusivamente ao mercado, sem preocupação aparente com o pensamento reflexivo e crítico. Referente a essa questão, o Parecer 29/2002 aborda que:

A moderna organização do setor produtivo está a demandar do trabalhador competências que lhe garantam maior mobilidade dentro de uma área profissional, não se restringindo apenas a uma formação vinculada especificamente a um posto de trabalho (CONSELHO NACIONAL DE EDUCAÇÃO, 2002, p. 18).

O Parecer destaca, ainda, que a educação profissional tem por concepção estratégica o acesso dos cidadãos a conquistas científicas e tecnológicas, pela qual impõe-se a superação do enfoque tradicional, que estava direcionado para a mera execução de tarefas em um determinado posto de trabalho.

Aparentemente, o CNST propõe apenas execução de um conjunto de tarefas, desconsiderando, ao que tudo indica, a preocupação com a pesquisa e, consequentemente, com a inovação. Nesse sentido, Pacheco (2011) alerta que como mecanismo de padronização: "[...] a globalização tece fortes laços tanto entre conhecimento e economia, como entre educação e formação [...]" (PACHECO, 2011, p. 16). Parafraseando ainda as palavras de Pacheco (2011), esses fortes laços estão associados à ideia de que se a mão de obra for de qualidade, bem-treinada pelos sistemas educacionais, existe um benefício econômico associado a esse desempenho.

Dentro desse contexto de busca por um bom desempenho econômico e mão de obra qualificada, parece cair no esquecimento o que Demo (2011, p. 1) chama atenção, para a questão da pesquisa. Esse autor explica que a pesquisa passa por um questionamento reconstrutivo, que "engloba teoria e prática, qualidade formal e política, inovação e ética" (DEMO, 2011, p. 1). E complementa: "Do ponto de vista da inovação, trata-se do conhecimento crítico e criativo" (DEMO, 2011, p. 1).

Embora os CSTs tenham características diferenciadas, como as próprias diretrizes abordam, é necessário superar a visão de que a formação tecnológica está aquém do que se tem projetado para os cursos de bacharelado com outras características. 
Ou seja, é relevante pensar em cursos tecnológicos que atendam à difusão da pesquisa científica e tecnológica, que avancem em pesquisas, inovação e criatividade, como definem a LDB e a Conferência Mundial do Ensino Superior de 2009.

Utilizar e aplicar novas tecnologias requer uma base teórica aprofundada
Em consonância, o Parecer 29/2002 aborda que os cursos tecnológicos têm a finalidade de "[...] desenvolvimento de competências profissionais que permitem tanto a correta utilização e aplicação da tecnologia e o desenvolvimento de novas aplicações ou adaptações em novas situações profissionais [...]" (CONSELHO NACIONAL DE EDUCAÇÃO, 2002, p. 23). Diante dessa afirmação, utilizar e aplicar novas tecnologias requer uma base teórica aprofundada, a qual se realiza por meio de pesquisa. "A pesquisa inclui sempre a percepção emancipatória do sujeito que busca fazer e fazer-se oportunidade, à medida que começa e se reconstitui pelo questionamento sistemático da realidade" (DEMO, 2011, p. 9). O autor complementa, ainda, que, quando se tem um sujeito crítico e criativo, é possível encontrar no conhecimento a arma mais potente para inovar.

Nesse sentido, observa-se que, embora a formação do tecnólogo seja mais densa na área tecnológica, não significa que não precise ter um conhecimento científico aprofundado. Quanto ao perfil profissional dos tecnólogos, o Parecer 29/2002 aborda:

O perfil profissional demandado e devidamente identificado constitui a matéria primordial do projeto pedagógico de um curso, indispensável para a caracterização do itinerário de profissionalização, da habilitação, das qualificações iniciais ou intermediárias do currículo e da duração e carga horária necessárias para a sua formação (CONSELHO NACIONAL DE EDUCAÇÃO, 2002, p. 30).

Diante disso, percebe-se a falta de conexão entre os documentos que organizam esses cursos. Na relevância para o pensamento crítico, reflexivo e avanço em pesquisa e desenvolvimento, que tanto é frisado na LDB e na Conferência Mundial sobre Ensino Superior de 2009, pouco se vê em relação a essas questões no Catálogo.

Demo (2011, p. 17) alerta para o fato de que o processo educativo está alicerçado em qualidade formal e política, a qual conjuga meios e fins por intermédio da competência, cidadania e competitividade. Diante dos argumentos de Demo (2011), pode-se remeter também ao que Pacheco (2011, p. 25) se refere quanto ao currículo: "A globalização reforça a centralidade do currículo como veículo de conhecimento, que passa a ser valorizado como recurso econômico". Os currículos pouco estão alinhados a pesquisa e inovação, pelo que se pode observar tanto no CNST como nos objetivos e perfis dos egressos.

Por conseguinte, nas Diretrizes vê-se que as tecnologias de ponta estão cada vez mais relacionadas com o conhecimento científico e "o papel de tecnólogo, de quem se espera uma aptidão para a aplicação da tecnologia associada à capacidade de contribuir para a pesquisa, se torna mais estratégico" (CONSELHO NACIONAL DE EDUCAÇÃO, 2002, p. 30). 


\section{Considerações finais}

O que se encontra nos documentos oficiais não se traduz na oferta, nos perfis profissionais e objetivos dos cursos superiores de tecnologia na questão da pesquisa e inovação. O que se espera da oferta de um curso tecnológico é condições de desenvolver competências e consciência profissional, sem estar completamente restrito a habilidades diretamente demandadas para área específica do mercado. Assim, grande parte dos cursos tecnológicos no Brasil ainda não é capaz de atender a essas finalidades.

Quando o curso superior é organizado em módulos, é mais difícil desenvolver um projeto de pesquisa que terá como meta um ensino superior. Sendo assim, não se tem nos cursos tecnológicos a interdisciplinaridade necessária. A grande questão aqui é que houve crescimento acelerado dos CSTs, mas sem estrutura adequada, sem deixar de ser um curso intermediário, aos moldes dos cursos de curta de duração criados nos anos 1960. Houve a troca de nomenclatura, mas junto com ela não foram revistos os princípios e as finalidades que um curso superior necessita ter.

Desse modo, a presente análise dos principais marcos conceituais que geraram avanços e retrocessos no desenvolvimento de cursos superiores de tecnologia no Brasil serve para investigações futuras sobre o perfil profissiográfico do tecnólogo e a relação entre a criação de cursos e o apoio à pesquisa e à inovação.

\section{Notas}

${ }^{1}$ Esta pesquisa contou com o fomento da Coordenação de Aperfeiçoamento de Pessoal de Nível Superior (Capes).

${ }^{2}$ De acordo com Santos (2011, p. 2) "Magnetron é uma válvula que gera micro-ondas, que são ondas eletromagnéticas, com comprimentos de ondas de $1 \mathrm{~mm}$ a $1 \mathrm{~m}$. As micro-ondas estão no espectro eletromagnético entre as ondas de rádio e infravermelho. Corresponde à frequência de 300 MHz até $300 \mathrm{GHz}$."

\section{Referências}

BARDIN, Laurence. Análise de conteúdo. Tradução Luis Antero Reto; Augusto Pinheiro. Lisboa: Ed. 70, 1977.

BRANDÃO, Marisa. Cursos superiores de tecnologia: democratização do acesso ao ensino superior?. In: ASSOCIAÇÃO NACIONAL DE PÓS-GRADUAÇÃO E PESQUISA EM EDUCAÇÃO, 29., 2006, Caxambú. Anais da $29^{a}$ reunião anual da ANPED. [S. I.]: ANPED, 2006. Tema: Educação, cultura e conhecimento na contemporaneidade: desafios e compromissos. Disponível em: http://29reuniao.anped.org.br/trabalhos/ trabalho/GT09-2018--Int.pdf. Acesso em: 16 mar. 2020. 
BRASIL. Lei n. 10.973, de 2 de dezembro de 2004. Dispõe sobre incentivos à inovação e à pesquisa científıca e tecnológica no ambiente produtivo e dá outras providências. Brasília, DF: Presidência da República, Casa Civil, 2004. Disponível em: http://www.planalto.gov.br/ccivil_03/_ato2004-2006/2004/lei/l10.973.htm. Acesso em: 16 mar. 2020.

BRASIL. Lei n. 4.024, de 20 de dezembro de 1961. Fixa as diretrizes e bases da educação nacional. Brasília, DF: Presidência da República, Casa Civil, 1961. Disponível em: http://www.planalto.gov.br/ccivil_03/leis/L4024.htm. Acesso em: 19 jul. 2013.

BRASIL. Lei n. 9.394, de 20 de dezembro de 1996. Estabelece as diretrizes e base da educação nacional - LDB. Brasília, DF: Presidência da República, Casa Civil, 1996. Disponível em: http://www.planalto.gov.br/ccivil_03/leis/19394.htm. Acesso em: 10 maio 2012.

BRASIL. Ministério da Educação. Catálogo Nacional de Cursos Superiores de Tecnologia. [Brasília, DF: Ministério da Educação], 2010. Disponível em: http:// catalogo.mec.gov.br/. Acesso em: 10 abr. 2014.

CONFERÊNCIA MUNDIAL SOBRE ENSINO SUPERIOR, 2009, Paris. As novas dinâmicas do ensino superior e pesquisas para a mudança e o desenvolvimento social. Paris: UNESCO, 2009.

CONSELHO NACIONAL DE EDUCAÇÃO (Brasil). Parecer n. 29, de $\mathbf{3}$ de dezembro de 2002. Diretrizes curriculares nacionais gerais para a educação profissional de nível tecnológico. Brasília, DF: Conselho Nacional de Educação, 2002. Disponível em: http://portal.mec.gov.br/cne/arquivos/pdf/cp29.pdf. Acesso em: 16 mar. 2020.

DEMO, Pedro. Educar pela pesquisa. 9. ed. Campinas: Autores Associados, 2011.

FAVA-DE-MORAES, Flavio. Universidade, inovação e impacto socioeconômico.

São Paulo em Perspectiva, São Paulo, v. 14, n. 3, p. 8-11, jul./set. 2000.

FUCK, Marcos Paulo; VILHA, Anapatricia Morales. Inovação tecnológica: da definição à ação. Contemporâneos: revista de artes e humanidades, São Paulo, n. 9, p. 1-21, 2012.

JUCÁ, Mario Cesar; OLIVEIRA, Paulo Jorge de; SOUZA, Romildo José de. Cursos superiores tecnológicos: um avanço da educação. In: COLOQUIO INTERNACIONAL SOBRE GESTIÓN UNIVERSITARIA EN AMÉRICA DEL SUR, 10., 2010, Mar Del Plata. Anais [...]. Mar del Plata: [s. n.], 2010. p. 1-11. Disponível em: https://core.ac.uk/ download/pdf/30378066.pdf. Acesso em: 16 mar. 2020. 
LÜDKE, Menga; ANDRÉ, Marli E. D. A. Pesquisa em educação: abordagens qualitativas. São Paulo: EPU, 1986.

NUNES, Danielle Duda. A Física na cozinha. 2008. Trabalho de Conclusão de Curso (Licenciatura em Física) - Universidade Católica de Brasília, Brasília, DF, 2008.

PACHECO, José Augusto Brito. Discursos e lugares das competências em contextos de educação e formação. Porto: Porto Editora, 2011. (Coleção panorama, 11).

PLONSKI, Guilherme Ary. Bases para um movimento pela inovação tecnológica no Brasil. São Paulo em Perspectiva, São Paulo, v. 19, n. 1, p. 25-33, jan./mar. 2005.

RICHARDSON, Roberto Jarry. Pesquisa social: métodos e técnicas. São Paulo: Atlas, 1999.

SEVERINO, Antonio Joaquim. Pesquisa, pós-graduação e universidade. Revista da Faculdade Salesiana, Lorena, v. 24, n. 34, p. 60-68, 1994.

STRYHALSKI, Patricia Murara. Cursos superiores de tecnologia no Brasil: tradução das políticas públicas do ensino superior nos documentos oficiais e perfis profissiográficos. 2016. Tese (Doutorado em Educação) - Universidade do Vale do Itajaí, Itajaí, 2016. 